\title{
Chemicals Used in Hydraulic Fracturing
}

\section{Possible Less Toxic Alternatives to the Chemicals used to Extract Natural Gas}

\author{
Tag Words: Environment; Hydraulic Fracturing; Fracking; Chemical Alternatives
}

Authors: Michael Dziedzic and Sherjeel Yaqoob with Julie M. Fagan, Ph.D.

\section{Summary}

This report will focus on the topic of hydraulic fracturing. It is a process that has been going on for many years, and is the main method of extracting natural gas beneath the Earth's surface. While it is known that natural gas is in fact a much cleaner fossil fuel and would be more cost beneficial for us to use, the process of hydraulic fracturing is still very risky and has been involved in a lot of concern for pollution. While this report will go into more detail of fracking itself, it will also explain the ongoing research that is being done to make this process "greener". The report will also include our own research that we have done to promote a safer method of fracking. We have used that research for a service project, which involved getting in touch with companies/corporations by letter and informing them of our research.

\section{You tube link}

\section{http://www.youtube.com/watch?v=t-fsRkn4eKQ}

\section{Energy - we all need it (JF)}

Every country on this earth is in need of energy. As the population grows, so does our need for energy. Relying on certain countries to supply a significant amount of the world's energy leads to economic and political instability. To become self sufficient, countries need to harness energy on their own soil. Relatively recently, there has been a surge in tapping the apparently vast supplies of natural gas embedded in the earth's rock. This process, called hydraulic fracturing, uses a technique first reported in 1949. Ever since then, gas companies have been using this technique which utilizes enormous quantities of waste that are mixed with toxic, cancer causing, hazardous chemicals. It is not clear much effort has been made by the gas industry since the inception of this technique to clean up their act by attempting to substitute the more toxic chemicals with safer, environmentally friendly chemicals.

\section{First- An Explanation of the Fracking Process (MD)}

Hydraulic fracturing is a process that is used in the oil and gas industry, but more commonly associated with natural gas. This process uses hydraulic pressure to fracture, or break up, shale rock thousands of feet underground where the porous reservoirs of natural gas are found. In the beginning of the process, workers must drill down vertically to where the natural gas is located. The drill will then be turned to a horizontal position (called horizontal drilling), and will continue on a certain distance (all the while a metal casing is used the entire path of the drill to hold it open).The drill is then pulled back up, now allowing water mixed with sand and specific chemicals to be pumped into the hole at extremely high pressures-this is the part where the fracking will occur. The metal casing that is used in the hole has pre-made holes in it towards 
the horizontal end to allow the mixture to push onto the surrounding rock. As the pressure builds up, the surrounding rock begins to fissure and break open, and will be held open by the sand (called the proppant here). Once the fracking process is completed, the fluid is then pumped back up the well (now called the fracking fluid), allowing the extraction of natural gas to begin. It has been said that while a well doesn't have to be constantly drilled, more than one "fracking" will be done on a well. [Ref 1]

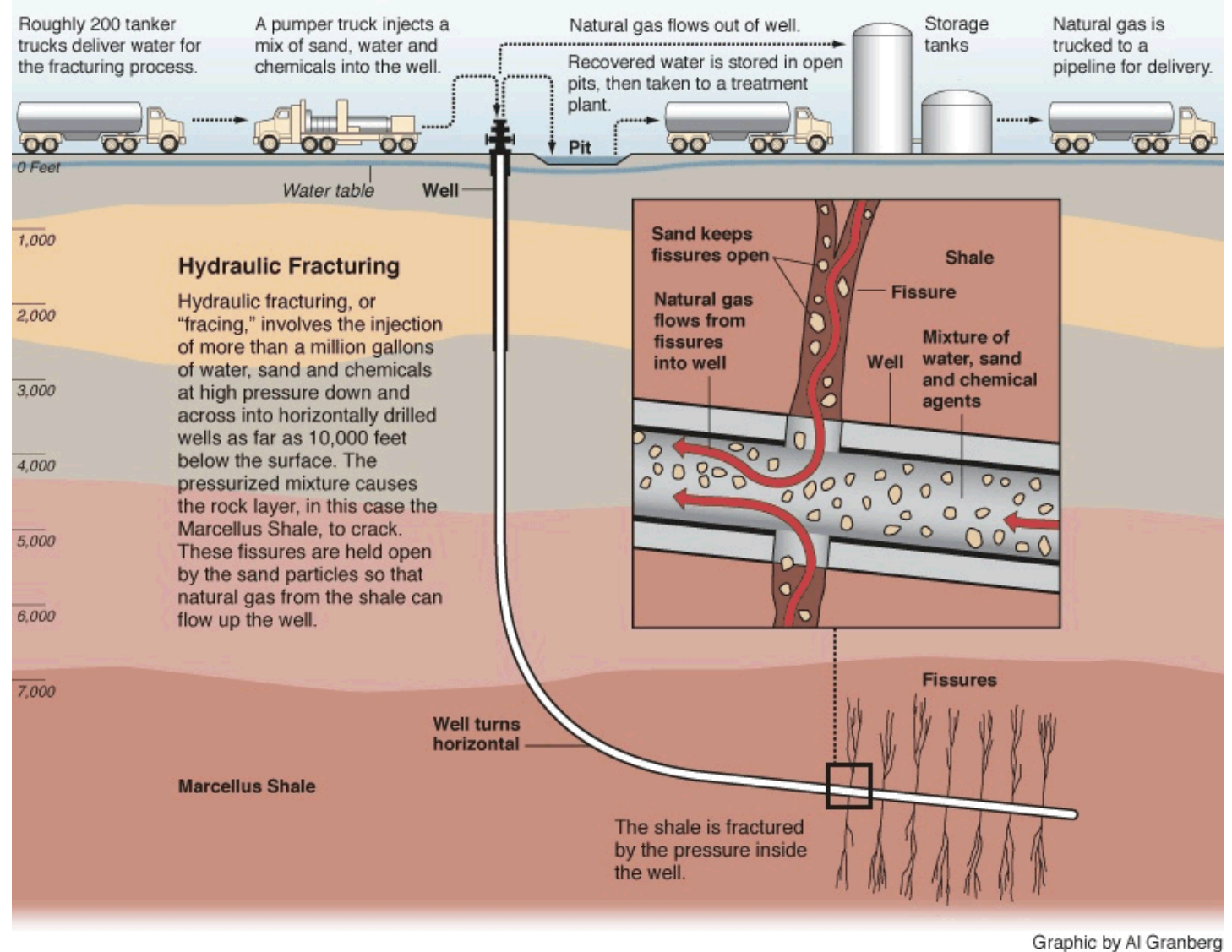

\section{A Brief History of Fracking (MD)}

Fracking has come a long way since the initial experiments with it. In 1949, Stanolind Oil did its first experimental frack in Grant County, Kansas. They injected one thousand gallons of napalm-thickened gasoline, followed by a gel breaker, $2400 \mathrm{ft}$. into the earth to frack limestone. Up until the 70's there was no wider usage of fracking.

The industry saw a boom in 2005 with the Energy Policy Act, which exempted it from compliance with the Safe Drinking Water Act, the Clean Air Act, and the Clean Water Act. This has come to be known as the Halliburton Loophole, which more specifically was for how fracking was exempted from the Safe Water Act (the EPA could only retain authority if a company was to use diesel fuel instead of water). Regulations were therefore left to the States, and have been piecemeal. This is also what has allowed the energy industry to keep the 
chemicals used in its fluids secretive over time. [Ref 30, 31]

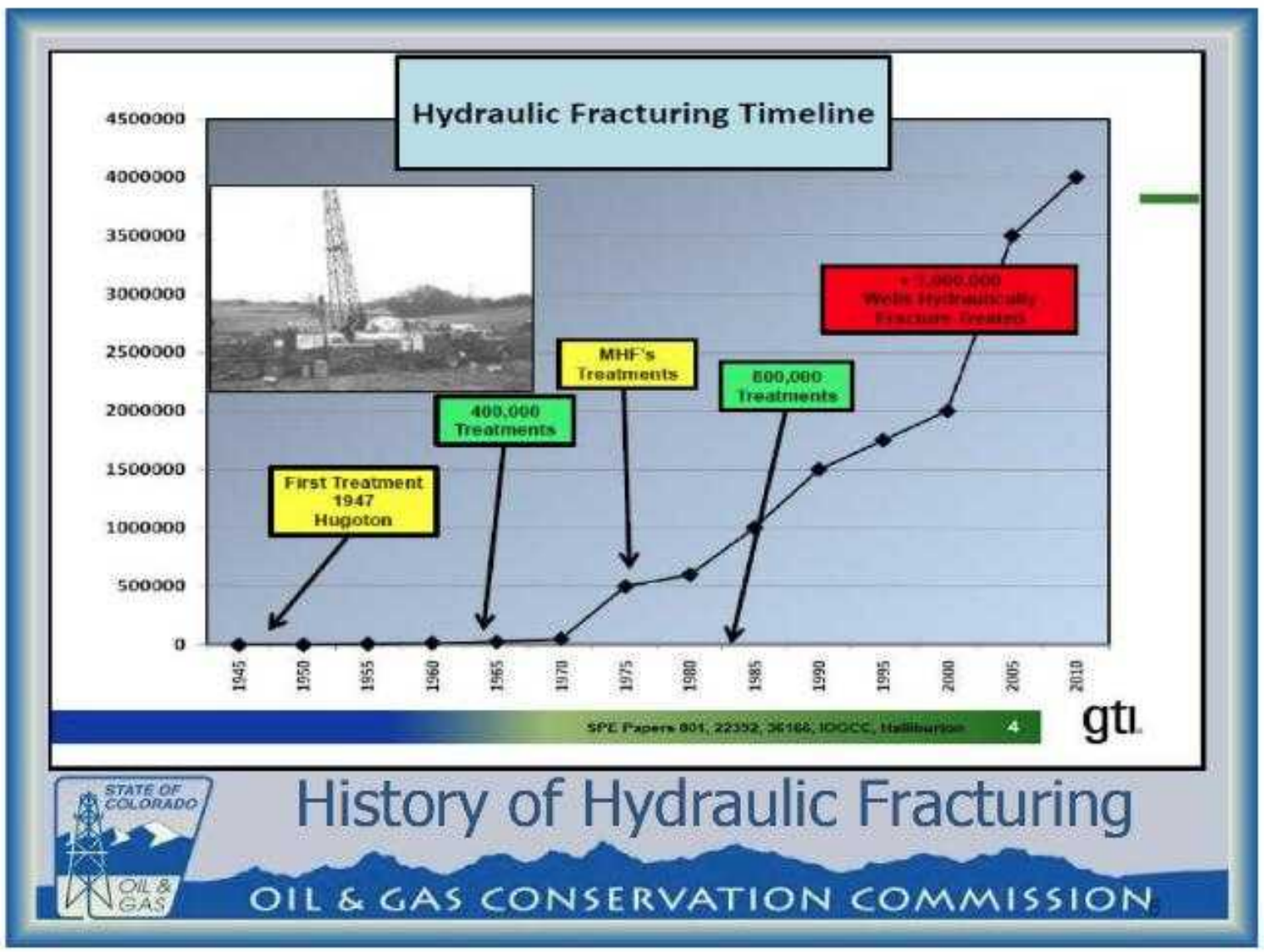

[Ref 30]

\section{The Benefits and Dangers (MD)}

The benefits of fracking are primarily economic reasons. Natural gas is in great abundance in North America (ex. Marcellus Shale), and can be sold at a price much lower than oil. An added plus here is greater usage of domestic resources as opposed to foreign. An added plus here is that not only are the resources cheaper due to not having to be shipped overseas, but natural gas can also be more easily transported in pipelines. In turn, more jobs are available due to the amount of work required. The extraction of natural gas also has environmental benefits, as this fossil fuel burns much cleaner than oil or coal. [Ref 1,2]

Dangers of hydraulic fracturing are primarily pollution due to the fracking process itself. First and foremost, hydraulic fracturing requires millions of gallons of freshwater each time. This leads to our next point which is that not all of the fracking fluid used can be recovered. What is recovered is no longer drinkable, which has primarily led to the solution of disposing this fluid in deep injection wells, never to be used again. In both cases of fracking fluid being underground, there has been serious concern for contamination of underground freshwater sources. States that have reported a decrease in drinking water quality (where fracking is definitely done) include AL, CO, NM, VA, WV, and WY. Some higher priority chemicals that are commonly found around hydraulic fracturing include: diesel fuel (sometimes replaces water, said to be more effective), methanol, formaldehyde, ethylene glycol, glycol ethers, HCL, sodium hydroxide, and 
polycyclic aromatic hydrocarbons. Fracturing is also known to release dangerous chemicals into the air-during a three to ten day process called "completion", which is needed for venting purposes. [Ref 1,2]

One famous-or infamous-claim by homeowners (more common in Pennsylvania) is that the chemicals that have seeped into the groundwater are now coming through faucets in their homes, and are concentrated enough to be ignited. This was seen in the documentary "Gasland", which explained the dangers that are present in Hydraulic Fracking. [Ref 3]

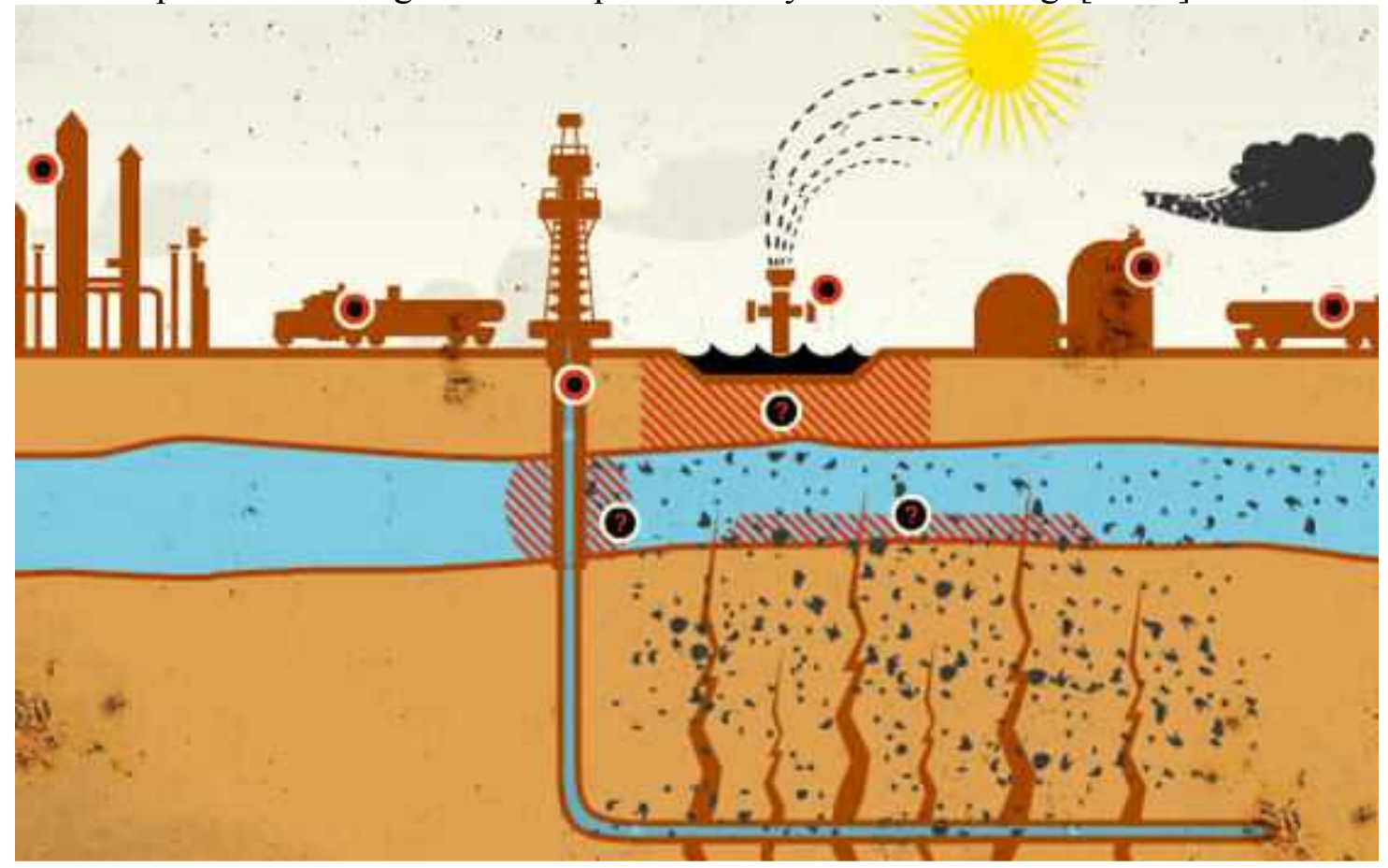

This image is a compilation of all the potential dangers and risks related to fracking. In relation to what this report will focus on, we can see that there is concern for the leaching of fracking fluid from the initial underground site to freshwater underground. Companies claim that their drilling takes place thousands of feet below these freshwater sites-which is true-but it has also been stated that the "fracking fissures" can extend very long distances. [Ref 5]

What we have talked about is just a small scope of the concerns and dangers present in hydraulic fracturing. While hydraulic fracturing can offer great rewards, caution and care must be taken, and it is believed that safer methods are available that should be considered. It is felt that this should be the ultimate goal: to protect the people and the environment by researching and implementing the newest and safest practices possible while still reaping the benefits of an inexpensive and cleaner resource. Therefore, this project will focus on the chemicals used in fracking, identifying their uses, and attempting to identify cleaner and safer alternatives. There will also be a focus on other research that is being done to improve on this process of extracting natural gas. 


\section{The Chemicals Involved (MD)}

The following is a list of the purposes of chemicals used in hydraulic fracturing, and what some of the more common chemicals actually are. More chemicals are involved, and will be available in the appendix. [Ref 6]

Acid: Helps dissolve minerals and initiate cracks in the rock (hydrochloric acid)

Biocide: Eliminates bacteria in the water that produces corrosive by-products (Glutaraldehyde, Quaternary Ammonium Chloride)

Breaker: Allows delayed breakdown of gel, product stabilizer (Ammonium Persulfate, sodium chloride)

Clay Stabilizer: Prevents clays from swelling or shifting (sodium chloride, Choline Chloride)

Corrosion Inhibitor: Product stabilizer and/or winterizing agent, prevents corrosion of pipe (isopropanol, formic acid)

Crosslinker: Maintains fluid viscosity as temperature increases (Boric acid, potassium metaborate)

Friction Reducer: "Slicks" water to minimize friction (Polyacrylamide)

Gelling agent: Thickens the water to suspend the sand (guar gum, polysaccharide blend)

Iron Control: Prevents precipitation of metal oxides (acetic acid, thioglycolic acid)

Non-Emulsifier: Prevents formation of emulsions in fracture fluid (lauryl sulfate)

pH adjusting agent: Adjusts the $\mathrm{pH}$ of fluid to maintain effectiveness of other components (sodium hydroxide, acetic acid)

Scale inhibitor: Prevents scale deposits in pipe (sodium polycarboxylate, phosphonic acid salt)

Surfactant: Carrier fluid for active surfactant ingredients (naphthalene)

Chemicals are used to dissolve minerals and initiate cracks in the rock, eliminate bacteria, "slick" the water to minimize friction, thicken the water to suspend the sand, prevent scale deposits in the pipe, prevent clays from swelling or shifting and more. [Ref 30]

\section{Alternatives to Fracking (MD and SY in all subsections)}

It has been found online that research and movements have been done (and are still being done) to completely change the way natural gas is recovered. Much of the research done has revolved around limiting the use of these chemicals; however it would seem that doing so would result in an increase in the usage of water.

\section{Hydrovibration}

One proposed alternative to the current method of drilling for natural gas is known as Cavitation Hydrovibration. This method uses a large, completely vertical drill, and a steady pressurized water flow (no chemicals are used). Essentially, as water is pushed through this drill it is done so in a resonating process, allowing the drill to "pulse" and impact the surrounding rock at a high frequency. Field tests have been successful; however this method has not actually been used yet for natural gas applications.

\section{Reusing Fracking Fluid}

Another means of dealing with the consequences of this problem is reusing fracking fluid. Instead of bringing in all fresh water, companies would process used fracking fluid with the intention of introducing it again in the fracking process. Unfortunately, some companies 
argue that the former method is easier and cheaper than recycling old fluid and therefore tend to not recycle used fluid. Despite this, states such as Pennsylvania are considering this option due to the limited amount of space that is available to dispose or leave the used fluid.

When the fluid goes into the formation, the fluid used is mostly water with some sand and chemicals, chemicals that are friction reducers, scale inhibitors, iron controls, and biocides. The flow back fluid which comes from the hole where the drilling is taking place contains salt which has been dissolved, and heavy metals. These contaminants are then dumped, which affects the environment and the human population around the dump site, causing health issues to people who drink this water contaminated by the leftover fluid. Flow back water is not simply reused because it can potentially close the opening to the natural gas and make the process of filtering this water very difficult. Thus, it is imperative that flow back water be treated in order to remove the harmful effects it exhibits when dumped and for it to be reused for the next fracking site. This treatment process would control the aforementioned chemical contamination and bacteria cultures that may form in the flow back water.

Despite some companies' hesitation to adopt this method of reusing fracking fluid due to financial concerns, there are two companies, Kroff Well Services Inc. and Superior Well Services Inc. that have collaborated to engineer a method to treat flow-back water for reuse in hydraulic fracturing. These companies have introduced a revolutionary method that both reduces the consumption of fresh water and addresses the need for the disposal of flow back. The effectiveness of this strategy has been substantiated by numerous trials at shale gas production sites where treated flow back fluid was the source water for the fracturing process fluid. The processing strategy addresses concerns that any operator will have when reusing water: shale, iron deposition, suspended solids, microorganisms that could form in the proppant pack, and appropriate $\mathrm{pH}$ and other water attributes needed to achieve adequate friction reduction. Many laboratory processes which include inductive coupled plasma analysis, and spectrophotometric and wet analytical titration testing, help check the state and content of the water before fracking. Many tests are done to the osmotic pressure, chemical oxygen demand, and microbiological concentrations. Analyzing this data helps determine the next course of action to take when filtering the water for the next fracking process. [Ref 21]

\section{Venting}

There has been recent push by the EPA in dealing with airborne chemicals during the venting process. Venting is when the shale - the location of natural gas underground - is opened. However, because the pressure released on the initial opening is so great, companies release the natural gas into the air until the pressure is reduced enough for them to extract the natural gas. Unfortunately, releasing the natural gas into the air has a detrimental effect on the atmosphere, therefore companies burn the excess amount of gas in order to address this problem. Standards are in place for companies to use additional smog-reducing technology on their wells that are hopefully more effective than the current procedure.

One particular gas, methane, has also been shown to have a detrimental effect on the atmosphere. Researcher Howarth published an analysis of greenhouse gases with the focus on methane or natural gas emissions and believed that electric generators should be used to correct this issue. In addition, he argued that methanol should only be used for 100 years because prolonged use could have a negative impact on the environment and contribute to global warming. He analyzed both electricity and heat production in an analysis of methane in 20 to 100 year duration, but the decade scale was important because it gave us the indicator of how much the climate will 
change. Howarth concluded that the green house emission of natural gas is more so than other fossil fuels in a 100 year time period, and while would be beneficial for us now, research into other forms of energy should be urged. [Ref 22]

\section{The Alternative Chemicals (SY, including all categories)}

Based on our reading on the subject, we have selected alternative chemicals that could possibly be used in place of the more toxic ones currently being used. They are safer for humans, are environmentally friendlier, and can be used for the same purposes of the currently used chemicals.

\section{A. Acids Alternatives}

One alternative has been identified as Emerald Safe. It is a blend of low $\mathrm{pH}$ organic salt which brings it to the acidity of HCL while reducing the corrosiveness to the skin and ferrous substrates. This chemical was found through Hubbard-Hall, a chemical distributor that deals in other environmentally safer chemicals as well. Unlike HCL the consumer will not exhibit the dangerous side effects such as severe abdominal pain, the swelling of the throat making it hard to breathe, severe chest pain, over salvation, severe fever, mouth pain, quick drop in blood pressure, severe throat pain, and vomiting which can include blood" [Ref 7]. Of course, these will vary on the concentration of HCL in water.

\section{B. Biocides Alternatives}

An alternative to glutaraldehyde is oxidised saline solution system (Sterilox), Sterilox helps give a 'high-level' disinfection, give you quick bacteria free water, all without impacting a person's health or the environment. [Ref 8]. The health effects of glutaraldehyde throat irritation, lung irritation, have a hard time breathing, asthma, nose pathway irritation, sneezing, burning sensation of eyes, and conjunctivitis [Ref 9].

An alternative to Quaternary Ammonium Chloride is a produced Lake Land chemical called Bromax which is the mixture of liquid Bromine and Chlorine, this solution is stronger than Sodium Hypochlorite in oxidizing materials which are biological. It is effective in lower doses, for example 2oz of Bromax can oxidize material in 1000 gallons of water [Ref 10]. Quaternary ammonium compounds can cause toxic effects by inhaling, consuming, and varies exposure to skin. Exposure to a weakened solution can still cause some mild irritations. A concentrated version of quaternary ammonium compounds can be corrosive which can burn the skin and in a person airway. [Ref 11]

\section{Breaker Alternatives}

Calcium Magnesium Acetate is usually used to de-ice but can be used in the fracking process because it is safe for environment, and since fracking involves a lot of water it is no more corrosive than water. Another plus is it's still safe even if it runs off into rivers or lakes safe for lake; it also poses no danger to animals. Sodium Chloride is corrosive, dangerous to vegetation, and very dangerous if the chemical gets on children or pets.

Another chemical used in breaking is called Ammonium Persulfate. Ingestion of this chemical will cause dizziness, diarrhea, soreness to the throat, and vomiting. When exposed to 
eyes it will cause pain and some redness appearing. When exposed to skin it will cause irritation, some redness, and pain. [Ref 12]

\section{Clay stabilizer Alternatives}

The Sodium Chloride alternative would be sea salt which is a natural alternative to a non organic salt. Also could use Calcium Magnesium Acetate

\section{E. Friction reducers Alternatives}

Lactic acid is a natural alternative to Boric acid, it comes the milk of a cow and just as effective as boric acid [Ref 13]. The short term effects of boric acid is it will cause irritation to the eyes, lungs, and dermal. Exposure to boric acid might also affect the function of the kidney, liver, and digestive tract. If a person is exposed constantly to boric acid then it may cause dermatitis, also in testing in animals it has shown to have a harmful effect on human reproduction. [Ref 14]

\section{F. Gelling agents Alternatives.}

One proposed alternative in this area is Tara Gum. Tara gum has a similar chemical configuration to guar gum. Tara gum is almost as soluble in cold water as guar gum. Tara gum can get as thick as guar gum, but the advantage of Tara gum is it flows in a more smooth, natural, while guar gum flow in a more melted plastic fashion. Also guar gum tends to have a string like characteristic and does not flow as naturally [Ref 15]. Guar gum is not known to cause any health effects, but some studies suggest that it may play a role in affecting metabolism.

\section{G. Iron control Alternatives}

Acetic acid is already a natural product but citric acid could also be used as a natural source. When exposed to eyes will cause some irritation but can be dealt with by flushing the eyes with water.

\section{H. Non Emulsifier}

Sodium Coco Sulfate, although the name of this detergent is pretty similar to sodium laureth sulfate, sodium coco sulfate appears safer than SLS in terms of carcinogenic byproducts. Unlike SLS, sodium coco sulfate does not lead to the formation of the carcinogen 1,4-dioxane as SLS can. Sodium coco sulfate is derived from coconuts, and is commonly used in toiletries marketed as "natural" or SLS-free. [Ref 16]

\section{I. pH Adjusting Agent}

Acetic acid is already a natural product but citric acid could also be used as a natural source. When exposed to eyes it will cause some irritation but can be dealt with by flushing the eyes with water. 


\section{J. Scale inhibitor Alternatives}

Phosphonic acid salt alternative is formic acid, can dissolve limescale more effectively then phosphonic acid salt. By making the salt more soluble you are risking less on salt deposits which can reduce the effectiveness of the acid. The calcium salt of formic acid is many times more soluble than Phosphonic acid salt [Ref 17]. The phosphonic acid salt can alter the body's ability use calcium, which can lead to osteoporosis, the softening of the bones or teeth. Phosphoric acid can also mess with the hydrochloric acid in your stomach making it difficult for the body to absorb properly nutrients and kill bacteria. [Ref 18]

\section{K. Surfactant Alternatives}

Using vinegar is a safer alternative to isopropyl alcohol. Vinegar can be used in some health applications, such people who suffer from eczema can use vinegar to reduce dryness and itching from the condition, it can be used to relieve poison ivy infection or cleaning out a infected ear. [Ref 19]. Drinking isopropyl alcohol can affect your central nervous system right away. The central nervous system controls the involuntary actions of the human body which includes the cardiovascular system, the respiratory system, and the gag reflex. By exposing yourself to Isopropyl alcohol it will slow down these functions, thus shutting them down which can lead to death. [Ref 20]

Not every category was shown here with an alternative; these were the Corrosion Inhibitor and Crosslinker categories. As seen in [Ref 6], these categories already have many alternatives, and therefore further research would not have been useful on our part.

\section{Conclusion: A Look at the Future (SY)}

The EPA is claiming to be studying and understanding what can be done to improve hydraulic fracturing methods. Currently, underground injection of wastewater fracking fluid is regulated by the Safe Drinking Water Act. Guidelines will soon be set for direct wastewater discharge through the Clean Water Act. The EPA also explains the re-use of fracking fluid, and how it is necessary but (as it is already known) a process not able to be completely implemented due to pollutant levels sometimes seen in fracking fluid. There is also work being done to close the Halliburton Loophole (as of 2012), hopefully to be implemented within the next couple of years, which would broaden the definition of diesel fuel. [Ref 29, 32] 


\section{The Service Project}

The next step after conducting our own research would be to somehow effectively get the word out about trying to use alternative chemicals in hydraulic fracturing. To us, this means contacting people who would have the most significant impact on the fracking process. Therefore, our service project will focus on companies/corporations that we feel would be the best to explain to the research we have done, and depending on what is more appropriate, either ask for their support or convince them to consider these alternatives.

The first approach would be contacting companies involved in fracking itself. Obviously, it would be most effective to contact companies that seem already to want to "move forward" and try to improve on hydraulic fracturing. As mentioned earlier in the report, two companies are already strongly looking to re-use fracking fluid, therefore these will be the fracking companies that we will talk to. These companies are Kroff Well Services Inc. and Superior Well Services Inc. The first one, Kroff Well Services, is located in Pittsburgh, PA, and is involved in wastewater treatment (so is not specifically a fracking company). The second company, Superior Well Services, is located in Indiana, PA, and is involved more in providing technologically advanced equipment to gas companies that are safer for the environment. Halliburton has offices located all across the world-the closest one seems to be in Canonsburg, PA. They are in the top ten of companies actually involved in fracking.

Another approach that's been considered is contacting the EPA-their website suggests that they do support feedback and comments, so it would be good to try to explain our thoughts to them as well. They have two regional offices nearby (both of which will be contacted), one in New York, NY and the other in Philadelphia, PA.

We have been able to identify non-profit organizations as well that have focused as a whole in finding new, innovative ways to provide clean energy and a focus on energy security. One such organization is the Environmental and Energy Study Institute, located in Washington, DC. Admittedly, their approach would be more on eliminating the use of fossil fuels, however they may appreciate our desire to at least improve on hydraulic fracturing for now. The same could be said for the Alliance to Save Energy, also located in Washington, DC.

The full address for each company/organization (as exactly seen on their websites) is as follows:

Kroff Well Services Inc.

One North Shore Center, Suite 450

12 Federal Street

Pittsburgh, PA 15212

Superior Well Services Inc. 121 Airport Professional Building Indiana, PA 15701

EPA Regional NY

290 Broadway

New York, NY 10007-1866

EPA Regional PA 
1650 Arch Street

Philadelphia, PA 19103-2029

Environmental and Energy Study Institute

1112 16th Street, NW, Suite 300

Washington, D.C. 20036-4819

Alliance to Save Energy

1850 M Street NW Suite 600

Washington, D.C. 20036

Halliburton

121 Champion Way, Suite 110

Canonsburg, PA 15317-5817 
The following is the letter that will be sent to these companies/organizations:

To Whom It May Concern,

This letter comes from students at the School of Environmental and Biological Sciences (SEBS) in Rutgers University. We are currently writing a report on Hydraulic Fracturing for our Ethics in Science class, and would like to take this opportunity to talk to you about what we have researched. The focus of this report has been researching the usage of chemicals in fracking, and attempting to find safer, cleaner alternatives that could possibly be used. Whether attempts have been made to use these alternatives or not, it would mean a lot to us if you could take a look at what we have come up with. Furthermore, the information that will be presented to you is a small part of the report that we have put together, which if you wish can be made available to you in its entirety.

Right now, our research has come up with this list of chemicals (or what we have seen as the more significant ones), and what their usage in Fracking is:

Acid: Helps dissolve minerals and initiate cracks in the rock (hydrochloric acid) Biocide: Eliminates bacteria in the water that produces corrosive by-products (Glutaraldehyde, Quaternary Ammonium Chloride)

Breaker: Allows delayed breakdown of gel, product stabilizer (Ammonium Persulfate, sodium chloride)

Clay Stabilizer: Prevents clays from swelling or shifting (sodium chloride, Choline Chloride) Corrosion Inhibitor: Product stabilizer and/or winterizing agent, prevents corrosion of pipe (isopropanol, formic acid)

Crosslinker: Maintains fluid viscosity as temperature increases (Boric acid, potassium metaborate)

Friction Reducer: "Slicks" water to minimize friction (Polyacrylamide)

Gelling agent: Thickens the water to suspend the sand (guar gum, polysaccharide blend)

Iron Control: Prevents precipitation of metal oxides (acetic acid, thioglycolic acid)

Non-Emulsifier: Prevents formation of emulsions in fracture fluid (lauryl sulfate)

pH adjusting agent: Adjusts the $\mathrm{pH}$ of fluid to maintain effectiveness of other components (sodium hydroxide, acetic acid)

Scale inhibitor: Prevents scale deposits in pipe (sodium polycarboxylate, phosphonic acid salt)

Surfactant: Carrier fluid for active surfactant ingredients (naphthalene)

From here, research was done to determine what chemicals could be used as safer alternatives, resulting in this list:

\section{A. Acids Alternatives}

One alternative has been identified as Emerald Safe. It is a blend of low $\mathrm{pH}$ organic salt which brings it to the acidity of HCL while reducing the corrosiveness to the skin and ferrous substrates. This chemical was found through Hubbard-Hall, a chemical distributor that deals in other environmentally safer chemicals as well. Unlike HCL the consumer will not exhibit the dangerous side effects such as severe abdominal pain, the swelling of the throat making it hard to breathe, severe chest pain, over salvation, severe fever, mouth pain, quick drop in blood pressure, 
severe throat pain, and vomiting which can include blood. Of course, these will vary on the concentration of HCL in water.

\section{B. Biocides Alternatives}

An alternative to glutaraldehyde is oxidised saline solution system (Sterilox). The health effects of glutaraldehyde are throat irritation, lung irritation, having difficulty breathing, asthma, nose pathway irritation, sneezing, burning sensation of eyes, and conjunctivitis [Ref 9].

An alternative to Quaternary Ammonium Chloride is a produced Lake Land chemical called Bromax which is the mixture of liquid Bromine and Chlorine, this solution is stronger than Sodium Hypochlorite in oxidizing materials which are biological. It is effective in lower doses, for example 2oz of Bromax can oxidize material in 1000 gallons of water [Ref 10]. Quaternary ammonium compounds can cause toxic effects by inhaling, consuming, and varies exposure to skin. Exposure to a weakened solution can still cause some mild irritations. A concentrated version of quaternary ammonium compounds can be corrosive which can burn the skin and in a person airway. [Ref 11]

\section{Breaker Alternatives}

Calcium Magnesium Acetate is usually used to de-ice but can be used in the fracking process because it is safe for environment, and since fracking involves a lot of water it is no more corrosive than water. Another plus is it's still safe even if it runs off into rivers or lakes safe for lake; it also poses no danger to animals. Sodium Chloride is corrosive, dangerous to vegetation, and very dangerous if the chemical gets on children or pets. Another chemical used in breaking is called Ammonium Persulfate. Ingestion of this chemical will cause dizziness, diarrhea, soreness to the throat, and vomiting. When exposed to eyes it will cause pain and some redness appearing. When exposed to skin it will cause irritation, some redness, and pain. [Ref 12]

\section{Clay stabilizer Alternatives}

The Sodium Chloride alternative would be sea salt which is a natural alternative to a non organic salt. Also could use Calcium Magnesium Acetate

\section{E. Friction reducers Alternatives}

Lactic acid is a natural alternative to Boric acid, it comes the milk of a cow and just as effective as boric acid [Ref 13]. The short term effects of boric acid is it will cause irritation to the eyes, lungs, and dermal. Exposure to boric acid might also affect the function of the kidney, liver, and digestive tract. If a person is exposed constantly to boric acid then it may cause dermatitis, also in testing in animals it has shown to have a harmful effect on human reproduction. [Ref 14]

\section{F. Gelling agents Alternatives.}

One proposed alternative in this area is Tara Gum. Tara gum has a similar chemical configuration to guar gum. Tara gum is almost as soluble in cold water as guar gum. Tara gum 
can get as thick as guar gum, but the advantage of Tara gum is it flows in a more smooth, natural, while guar gum flow in a more melted plastic fashion. Also guar gum tends to have a string like characteristic and does not flow as naturally. Guar gum is not known to cause any health effects, but some studies suggest that it may play a role in affecting metabolism.

\section{G. Iron control Alternatives}

Acetic acid is already a natural product but citric acid could also be used as a natural source. When exposed to eyes will cause some irritation but can be dealt with by flushing the eyes with water.

\section{H. Non Emulsifier}

Sodium Coco Sulfate, although the name of this detergent is pretty similar to sodium laureth sulfate, sodium coco sulfate appears safer than SLS in terms of carcinogenic byproducts. Unlike SLS, sodium coco sulfate does not lead to the formation of the carcinogen 1,4-dioxane as SLS can. Sodium coco sulfate is derived from coconuts, and is commonly used in toiletries marketed as "natural" or SLS-free. [Ref 16]

\section{I. pH Adjusting Agent}

Acetic acid is already a natural product but citric acid could also be used as a natural source. When exposed to eyes it will cause some irritation but can be dealt with by flushing the eyes with water.

\section{J. Scale inhibitor Alternatives}

Phosphonic acid salt alternative is formic acid, can dissolve lime scale more effectively then phosphonic acid salt. By making the salt more soluble you are risking less on salt deposits which can reduce the effectiveness of the acid. The calcium salt of formic acid is many times more soluble than Phosphonic acid salt [Ref 17]. The phosphonic acid salt can alter the body's ability use calcium, which can lead to osteoporosis, the softening of the bones or teeth. Phosphoric acid can also mess with the hydrochloric acid in your stomach making it difficult for the body to absorb properly nutrients and kill bacteria. [Ref 18]

\section{K. Surfactant Alternatives}

Using vinegar is a safer alternative to isopropyl alcohol. Vinegar can be used in some health applications, such people who suffer from eczema can use vinegar to reduce dryness and itching from the condition, it can be used to relieve poison ivy infection or cleaning out a infected ear. [Ref 19]. Drinking isopropyl alcohol can affect your central nervous system right away. The central nervous system controls the involuntary actions of the human body which includes the cardiovascular system, the respiratory system, and the gag reflex. By exposing yourself to Isopropyl alcohol it will slow down these functions, thus shutting them down which can lead to death. [Ref 20] 
This list is what we have compiled as possible chemical alternatives to be used in Hydraulic Fracturing. To the companies more involved in the Fracking process, we ask that you take consideration in what we have researched, and possibly find ways to implement the usage of these chemicals. To the organizations, we ask that you please support our work, and help us to convince those companies that if these alternatives are friendlier to the environment and humans that they should be used. A collaboration between gas companies and other researching organizations might be beneficial as well to further our understanding. We understand that some companies and organizations are already finding ways to improve on Hydraulic Fracturing, to understand it better in all aspects and to make it safer. We simply hope that this research can help in some way. Any comments or suggestions to our work would be greatly appreciated as well, our goal here is to have as much information as possible on the subject. Again, we thank you for your time to read this and consider what we have brought together.

\author{
Michael Dziedzic \\ Rutgers SEBS Student \\ mpd105@hotmail.com \\ Sherjeel Yaqoob \\ Rutgers SEBS Student \\ Sherjeel786@gmail.com \\ Julie M. Fagan, Ph.D. \\ Rutgers Professor \\ fagan@rci.rutgers.edu
}

After sending out these generic letters, it was decided that this message should be extended even further to other significant people. The first contact that we decided on was Steven Chu, Secretary of Energy to the Obama administration. His focus has been on alternate and renewable energy, reducing dependence on foreign oil, and creating more jobs. An alternate letter will be sent to his email address.

After emailing this to Steven $\mathrm{Chu}$, we also decided to contact the America's Natural Gas Alliance. Their website talks about how they are promoting the economic, environmental, and national security benefits of the usage of domestic natural gas. They represent 30 of North America's largest independent natural gas exploration and production companies.

Mr. Chu's email address: The.Secretary@hq.doe.gov

ANGA's Contact address: info@anga.us 
This letter comes from students at the School of Environmental and Biological Sciences (SEBS) in Rutgers University. We are currently writing a report on Hydraulic Fracturing for our Ethics in Science class, and would like to take this opportunity to talk to you about what we have researched. The focus of this report has been researching the usage of chemicals in fracking, and attempting to find safer, cleaner alternatives that could possibly be used. Whether attempts have been made to use these alternatives or not, it would mean a lot to us if you could take a look at what we have come up with. Furthermore, the information that will be presented to you is a small part of the report that we have put together, which if you wish can be made available to you in its entirety.

Right now, our research has come up with this list of chemicals (or what we have seen as the more significant ones), and what their usage in Fracking is:

(The next section of this letter will use the chemical categories and alternatives that were used in the first letter of our service project).

This has been what the focus of what our project is all about. Included in our report as well is some of the other research and advancements that are currently being done in relation to hydraulic fracturing, such as Cavitation Hydrovibration and future policies that the EPA wishes to implement as far as the venting process. We feel that further research should be done in the area we have studied, as we also feel that fracturing is not a process that will completely go away anytime soon and should be done in the safest and cleanest way possible. However, we do hope that our initiative can help in some way, regardless of how small the impact of alternative chemical usage may be.

Thank you for taking the time to read this and consider what we have done over the course of three weeks, and we hope to hear from you in the future.

\author{
Michael Dziedzic \\ Rutgers SEBS Student \\ mpd105@hotmail.com \\ Sherjeel Yaqoob \\ Rutgers SEBS Student \\ Sherjeel786@gmail.com \\ Julie M. Fagan, Ph.D. \\ Rutgers Professor \\ fagan@rci.rutgers.edu
}




\section{Editorial Letters}

Dear Editorial

As you know about the incident of hydraulic fracturing occurring in the US. Specifically local to NJ the proposed hydro-fracking in upstate NY which wishes to drill for natural gas, but people fear that the fracking process will contaminates the famous New York drinking watering. Once contaminated it will make it impossible to restore to its previous state after the fracking process. In a class project at Rutgers we are trying to prevent the problem before it begins by having greener chemicals, if you look at the list of chemicals here http://tinyurl.com/cu3j8st, you will see how exhausting this list is and imagine all that in our drinking water. All I want to point out is this, if we replaced just a few chemicals we can prevent a problem before it begins. You can for example a chemical used to restrict friction is call Boric acid can be substituted for a natural solution call lactic acid which is derived from milk. A small change can multiply into many changes but we need to let the word out to accelerate the process.

Sherjeel Yaqoob

I wanted to quickly talk about a petition that I am running involving hydraulic fracturing. The petition is for a group project at Rutgers University, and has to do with the chemicals involved in the fracking process. More information about fracking, and some of the chemicals used can be found on the webpage for the petition.

http://www.ipetitions.com/petition/changes-in-chemicals-used-in-hydraulic-fracking/

Michael Dziedzic

(To eletters@starledger.com) 


\section{References}

http://www.milliondollarwayblog.com/2011/07/top-ten-fracking-companies.html

Names of fracking companies

http://www.heatingoil.com/articles/hydraulic-fracturing-hydrofracking-the-risks-and-rewards-ofthe-controversial-drilling-technique1130/5/

Explanation of fracking, benefits and dangers [Reference 1]

http://michiganradio.org/post/fracking-natural-gas-benefits-and-risks

Benefits and risks of fracking [Reference 2]

http://oecotextiles.wordpress.com/2010/03/04/what-does-fracking-have-to-do-with-our-drinkingwater/

Gasland [Reference 3]

http://en.wikipedia.org/wiki/File:EIA_World_Shale_Gas_Map.png

World Shale Map [Ref 4]

http://blogs.dallasobserver.com/unfairpark/2011/02/following_report on the fracki.php

Compiled image [Reference 5]

http://fracfocus.org/chemical-use/what-chemicals-are-used

List of all chemicals and their uses [Reference 6]

Compiled list of Alternative "Greener" Chemicals

http://tinyurl.com/c7osybe [Reference 7]

http://tinyurl.com/crusxwx [Reference 8]

http://tinyurl.com/cxwwafs [Reference 9]

http://tinyurl.com/dyh8wwq [Reference 10]

http://tinyurl.com/c7osybe [Reference 11]

http://tinyurl.com/bvmhe7r [Reference 12]

http://tinyurl.com/bmhb8ee [Reference 13] 
http://tinyurl.com/cklgndo [Reference 14]

http://tinyurl.com/blqn2mo [Reference 15]

http://tinyurl.com/6pgb8yu [Reference 16]

http://tinyurl.com/cuzlehh [Reference 17]

http://tinyurl.com/bbrqpe [Reference 18]

http://tinyurl.com/7w9ky71 [Reference 19]

http://tinyurl.com/cvj57xn [Reference 20]

http://tinyurl.com/cveqtxh [Reference 21]

Research involving the reuse of fracking fluid

http://tinyurl.com/cepleml [Reference 22]

Research on the effect of venting in the fracking process

http://www.dianesays.com/chemicals-used-in-hydrofracking/

More info on chemicals used [Reference 23]

http://smarteconomy.typepad.com/smart economy/2009/12/a-green-alternative-tochemicalbased-hydraulic-fracturing-or-fracking-for-shale-gas-drillingcavitati.html Cavitation Hydrovibrator [Reference 24]

http://www.greenpeace.org/usa/en/campaigns/global-warming-and-energy/TheProblem/fracking/Environmental-Impacts-Recycled-Fluid/

Info on recycling fluid [Reference 25]

http://www.hubbardhall.com/9a8ceaa2-6a67-41a3-baf4-686d98b2ce46/resources-newsletterarchive-delivery.htm

Hubbard Hall-Emerald Safe Atl. to HCL [Reference 26]

http://www.huffingtonpost.com/2012/04/18/epa-fracking-regulations-obama_n 1434524 .html EPA on venting [Reference 27] 
http://online.wsj.com/article/SB10001424052702303404704577313741463447670.html

EPA backpedal [Reference 28]

http://www.epa.gov/hydraulicfracture/

EPA's page on fracking [Reference 29]

http://www.savecoloradofromfracking.org/basics/history.html

History of Fracking, other info [Reference 30]

http://www.counterpunch.org/2009/05/29/drilling-the-marcellus-shale-through-the-halliburtonloophole/

Halliburton Loophole [Ref 31]

http://www.bloomberg.com/news/2012-02-01/epa-shrinking-halliburton-loophole-threatens-

obama-gas-pledge.html

Closing the Loophole [Ref 32]

http://www.marketingforthemasses.com/lessons-from-the-field-a-tale-of-shale-drill

U.S. Shale Map [Ref 33]

http://www.swsi.com/index.php

Superior Well

http://www.kroff.com/default.aspx

Kroff

http://www.halliburton.com/

Halliburton fracking company

http://ase.org/

Alliance to Save Energy

http://www.eesi.org/

Environmental and Energy Study Institute 


\section{Appendix}

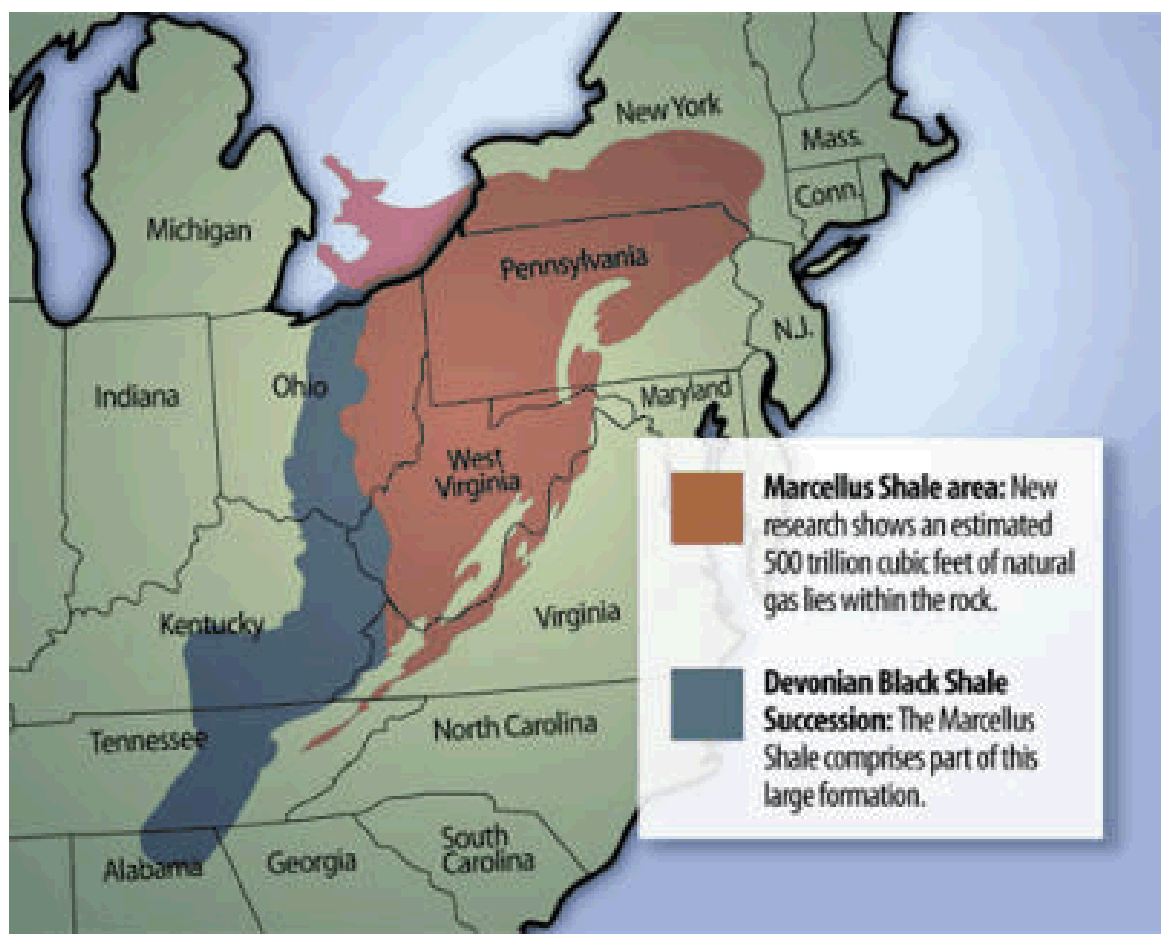

The picture shows that the North East Coast sits on a relatively large reservoir of natural gas-one that could supply the country for a very long time. [Ref 1]

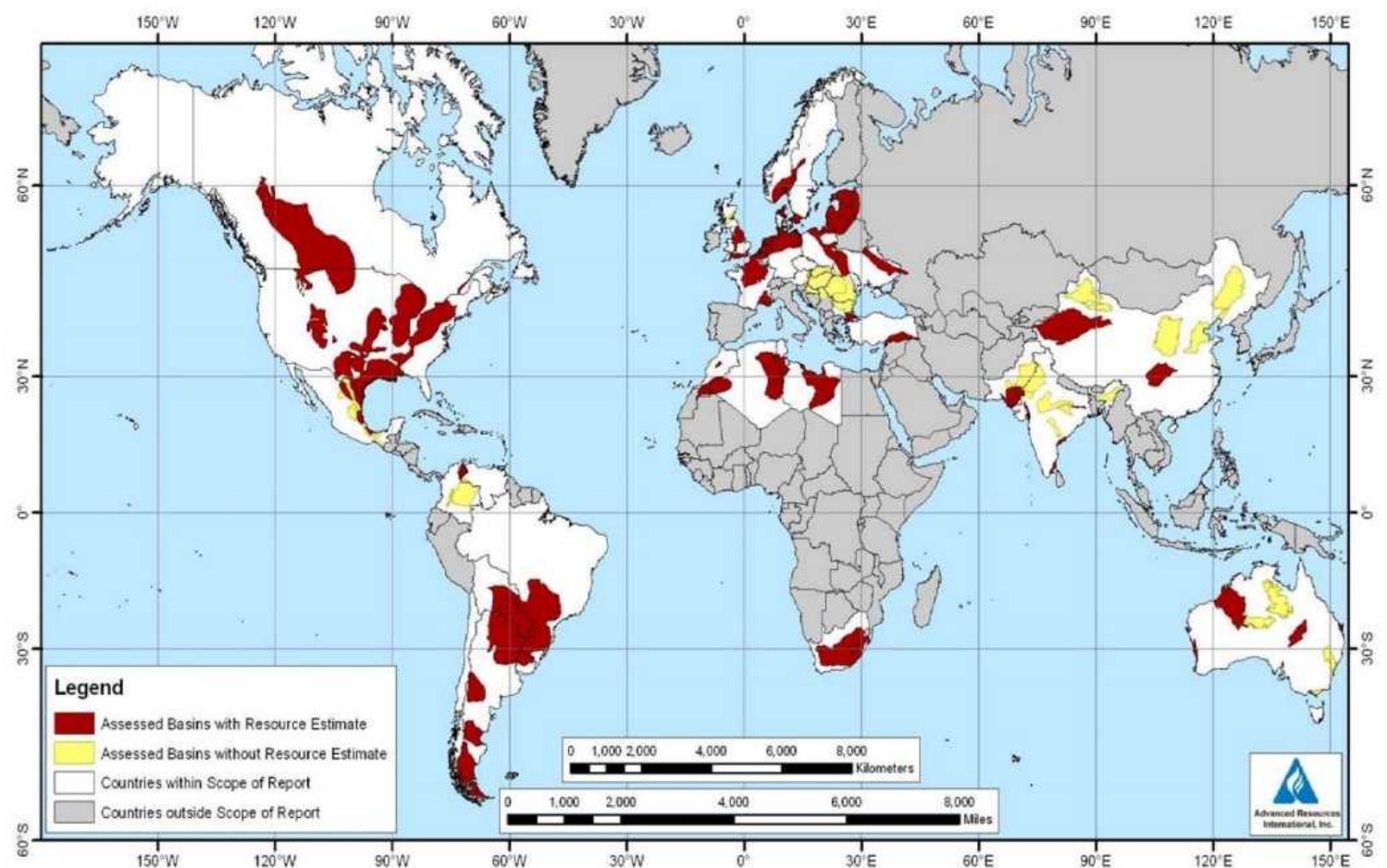

This map shows a comparison of shale deposits around the world. It can be seen that North America holds the largest deposits. [Ref 4] 


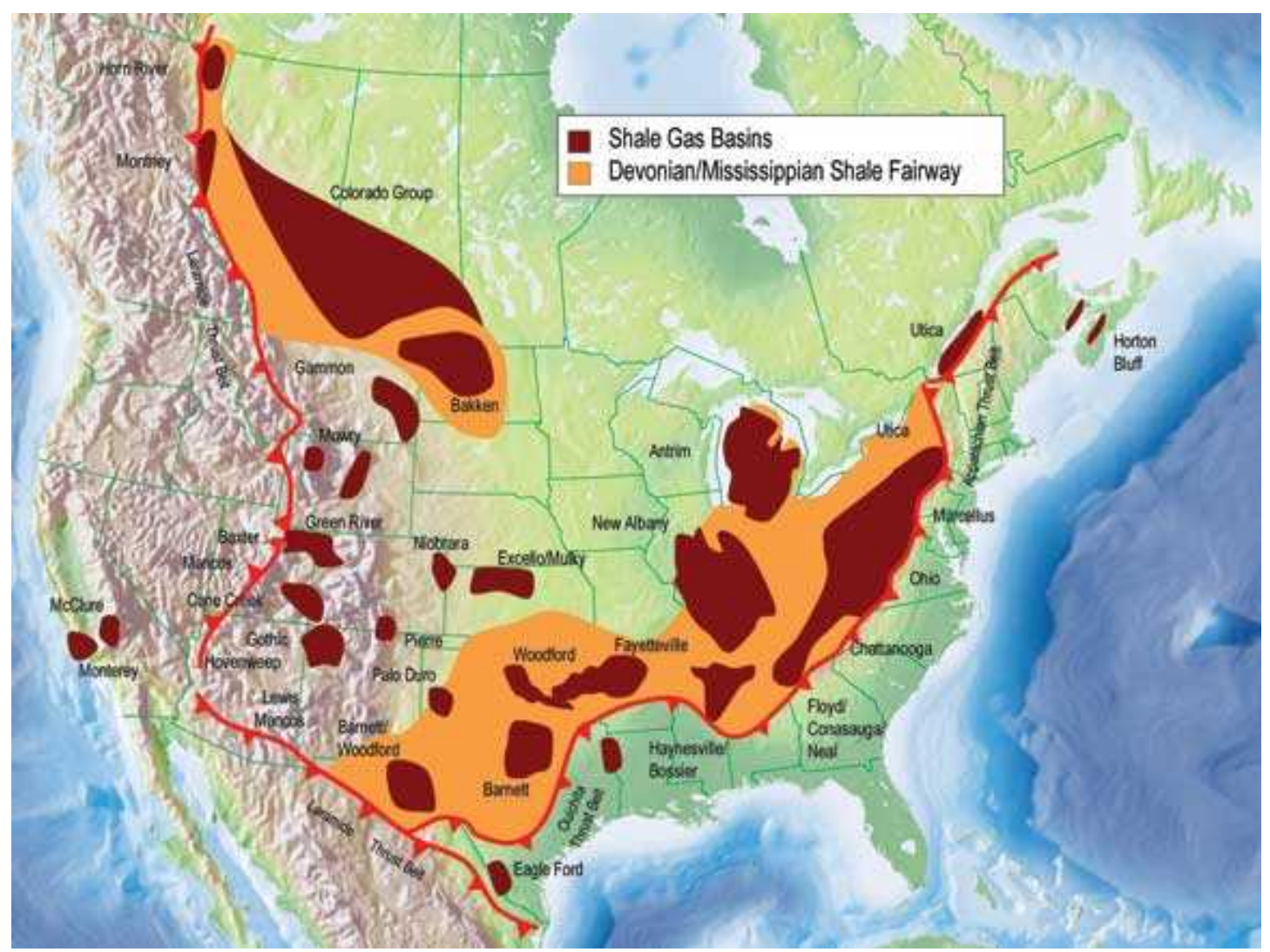

This image gives a more detailed look at shale and gas deposits around the country. [Ref 33]

The following link will provide a much larger list of the additives that are present in fracking fluid:

http://www.dianesays.com/chemicals-used-in-hydrofracking/ 